\title{
A propósito de los legionarios británicos: la primera expedición
}

\author{
Andrés Vargas Vega*
}

\section{Resumen}

El presente artículo busca retomar la temática iniciada en el tercer capítulo de mi monografía de grado, temática que corresponde a los expedicionarios europeos, generalmente de procedencia inglesa, que se enlistaron bajo las banderas de la revolución y combatieron en los ejércitos de Bolívar. Este artículo no sólo intenta referenciar la participación de militares extranjeros en las guerras de Independencia, sino que a la vez construye una valoración sobre el impacto de la influencia británica en dicho proceso

\section{Palabras clave}

Legionarios británicos, guerras de Independencia, Simón Bolívar, Historia Militar, Nuevo Reino de Granada.

\section{Abstract}

The present article wants to take up again the matter iniciated on the third chapter of my grade monograph, who is concerning to the european expeditionaries, generally of English origin, and who were listed under the flags of the revolution and fought in the Bolivar's armies. This article not only tries to index the participation of foreign military men in the Independence wars, but simultaneously constructs a valuation on the impact of the British influence in the above mentioned process

\section{Key words}

British Legionaries, Independence Wars, Simón Bolívar, Military History, New Kingdom of Granada

\section{A modo de introducción}

Creemos esencial hacer aclaración acerca de porqué los fenómenos y procesos históricos que tienen que ver con la institución militar, ya sea esta la protagonista principal o periférica, han sido generalmente relegados al olvido.

Un vacío de tal talante es incluso más reprochable, por cuanto que es una condición inherente a nuestro desarrollo histórico como proyecto político independiente, el haber sufrido los rigores del conflicto; tal aseveración no es nueva; ya en el siglo XIX Rafael Núñez lo había entrevisto así, lo que le llevó a

\footnotetext{
*Artículo tipo 2: de reflexión, según clasificación de Colciencias. Resultado de la Tesis de Grado presentada como requisito para obtener el título de Historiador de la Facultad de Humanidades de la Universidad del Valle, abril de 2008.

** Historiador de la Universidad del Valle. Coordinador del proyecto Historia Hoy, del Ministerio de Educación. E-mail: dalatriste78@hotmail.com.
} 
afirmar que: "En la historia de Colombia la paz es excepción, y la guerra la regla" (Ocampo López, 1994, p. 258).

La Conquista y su guerra de exterminación indígena, -un trabajo "eficiente" para haber sido hecho sólo con hachas y espadas- el estado de permanente alerta de las autoridades españolas ante los recurrentes alzamientos de las clases vasallas durante la etapa colonial, la destructiva y aniquilante guerra de independencia, las nueve guerras civiles generalizadas", junto con los más de setenta alzamientos, rebeliones, golpes de cuartel, pronunciamientos y guerras civiles parciales del siglo XIX (Pardo Rueda, 2004, p. 33) ${ }^{1}$, las guerras internacionales, La Violencia y su infame heredera: la Narcoviolencia; un siglo XX virtualmente vivido en Estado de Sitio; todos estos son elementos que refuerzan la opinión de que la historia de Colombia ha sido modelada por y en la guerra.

Siendo esto entonces algo axiomático, ¿Cuál es la razón de que se hayan ignorado reiteradamente los estudios sobre la institución militar? ¿Por qué los investigadores y la academia en general se muestran tan reticentes a la hora de involucrarse en una materia que inserte a la milicia como un actor influyente de nuestro desarrollo histórico? ¿Cuál es la causa de que la producción historiográfica sobre la institución armada en Colombia sea virtualmente nula? y que, dicho sea de paso, la que generalmente se produce es escrita o por extranjeros, o por miembros de las fuerzas armadas, generalmente en publicaciones restringidas al circulo militar, de muy pobre difusión y de calidad discutible; y sobre todo por qué, si el conflicto aún está presente, ignoramos su presencia y priorizamos el estudio de otro tipo de problemáticas, que si bien no dejan de tener su validez, no alcanzan a proyectar la importancia e incontestabilidad de nuestro propio conflicto endémico e intestino.

Las razones para tal desconocimiento, voluntariamente ignorado, de un actor fundamental en nuestro decurso histórico ameritarían para sí mismo un ensayo aparte ${ }^{2}$, pero nuestro juicio particular -y abierto con rigurosidad a la discusión- es que la academia no ha percibido a la milicia como opción a historiar en la creencia de que un acercamiento a tal materia los alinearía ideológicamente con el ejército,

\footnotetext{
* Entre estas está la Guerra de los Mil días, el segundo conflicto fratricida más destructivo a nivel del continente americano, sólo superado por la guerra civil norteamericana.

${ }^{1}$ A pesar de que ha sido muy criticado, su detallada recopilación de los conflictos lo hace de obligatoria consulta. En la introducción del libro se hace una descripción sucinta pero acertada de los más representativos, mismos que se amplían en el desarrollo del libro; si lo que se quiere es un acercamiento al fenómeno de la Violencia como tal se pueden consultar textos de reconocida trayectoria, que ya se han convertido en referente obligado para los investigadores como puede ser el caso de Guerrilleros y Soldados de Russel Ramsey, o La violencia en Colombia de Fals Borda, Guzmán Campos y Umaña Luna; por otro lado si la intención es un acercamiento más actual en cuanto a su proyección hacia el presente se puede consultar Las guerras civiles desde 1830 y su proyección en el siglo XX, de Alonso Valencia, Comp.

${ }^{2}$ Un escrito del profesor Adolfo León Atehortúa aborda esa problemática, Atehortúa afirma: "La persistente ascendencia positivista sobre los estudios históricos, el escaso desarrollo de la sociología en nuestro país y las circunstancias lógicas de un país en guerra, han afectado de manera particular las investigaciones referidas a la institución militar y sus relaciones con la sociedad civil". Atehortúa Cruz, A. (2004, mayo - agosto). Análisis Político, $N^{\circ}$ 51. p. 13.
} 
y por consiguiente con el stablishment. La academia como tal deja entonces por fuera a uno de los protagonistas principales en la historia de Colombia, y mientras esta tendencia se mantenga, no importa cuántos estudios y exploraciones contribuyan a enriquecer el acerbo historiográfico de nuestra nación, este seguirá forzosamente incompleto, inacabado, y las lagunas investigativas se mantendrán de manera indefinida hasta que tal error se subsane.

\section{Las convulsiones de la Europa}

A partir de 1792 la casi totalidad del continente europeo se va a ver sacudido por una guerra que socavará los cimientos de la forma de gobierno imperante: la monarquía.

Francia va a ser la nación que iniciará la conflagración y desde donde se irradiará la ideología que pondrá a la revolución, a la autodeterminación de los pueblos y a la destrucción del odiado absolutismo monárquico sobre el tapete.

Este país por sí solo, destronará y ejecutará a su monarca, emitirá la primera declaración de igualdad entre todos los hombres, se comprometerá a llevar y a apoyar la revolución, concediendo "fraternidad y ayuda a todos los pueblos que deseen recuperar su libertad, allá en donde esta sea necesaria" (Montgomery, 1968, p. 342), destruirá -recién salida de la revolución- a cuanto ejército y coalición se le ponga enfrente; y será su adalid, Napoleón Bonaparte, el causante directo del estallido de las revoluciones de independencia en los pueblos hispanoamericanos. Las guerras napoleónicas van a fracturar y a desorganizar las tradicionales monarquías, y si bien es cierto que para 1816 las tradicionales casas reales europeas ya habrán sido restauradas y el statu quo vuelto a imponerse, el retorno al absolutismo será más aparente que real y durante el resto del siglo XIX se sucederán con asombrosa reiteración, los levantamientos de los pueblos de la Europa para vindicar la autodeterminación.

Su principal oponente en Europa, -de hecho el único que estaba en capacidad de hacerlo, en gran medida debido a su condición de isla- la Inglaterra, cargará sobre sus hombros la responsabilidad de derrotar a uno de los más grandes capitanes militares de la historia; ya que si Francia llegare a consolidarse en el continente, la hegemonía de Albión tocaría rápidamente a su fin; para ello debió ampliar su aparato militar de forma exponencial y abrir su ejército -enteramente profesionalal reclutamiento civil.

Cuando después de Waterloo la amenaza napoleónica por fin desaparece y con el peligro a buen recaudo en Santa Helena, Inglaterra va a tener en filas a más de 500 mil soldados, a los que tendrá rápidamente que licenciar y los cuales no estarán preparados para retornar a la vida civil; a pesar de que la isla se había impuesto al -hasta el encumbramiento continental europeo de Hitler- más grande peligro para su existencia, su situación en la posguerra napoleónica no será la ideal. 
Luis Cuervo Márquez, uno de los pocos que se han referido al tema de los legionarios observa:

[...] Las malas cosechas de 1816 y la reactivación de las fábricas de la Europa continental le quitaron participación del mercado a los ingleses. Resultante de esto fue un menor número de empleados en las fábricas y un aumento en el número de parados que llegó a cotas muy altas en ciudades industriales como Birmingham, Liverpool, Londres o Dublín, en donde 60 mil personas recibían auxilios parroquiales.

El licenciamiento de las tropas, que habían regresado después de la campaña, aumentaba el número de indigentes, pues los soldados habían perdido hábitos de trabajo $\mathrm{y}$, además no lo encontraban aun cuando hubieran deseado conseguirlo.

En 1818, 60 mil hombres de guarnición en Francia volvían habituados a una vida que no podían continuar en la pobreza en que se encontraba el país (1938, p. 306).

Amén de los problemas de una economía en franca recesión, a causas de los enormes desembolsos requeridos para continuar la guerra, se sumaba el subsiguiente torrente tributario decretado, necesario por cuanto era urgente equilibrar las finanzas del Estado.

El profesor Alfred Hasbrouck, precursor en cuanto a estudios sobre los expedicionarios diserta, en su obra de 1928, sobre la situación de estos ex soldados:

Estos miles de oficiales y soldados súbitamente se vieron sin empleo, para ver por sí mismos y continuar su estilo de vida. Una considerable parte de estos hombres se habían enrolado para un largo tiempo y habían renunciado a las costumbres de la vida civil. Muchos de ellos, que habían visto mucho mundo, vieron en la revolución Americana la oportunidad de continuar sus carreras militares y mejorar su fortuna (p. 38).

Inglaterra estaba atravesando por un difícil momento, momento que era tan claramente desesperado que a veces tomaba visos de revolución; así al menos lo deja entrever Aquiles Echeverri M, escritor antioqueño que vertió al papel el accionar de un médico inglés, el doctor Hugo Blair Brown, durante la guerra de independencia, y que posterior a esta contribuirá ampliamente con la difusión de la medicina en la provincia de Antioquia:

[...] Todos estos antecedentes, crearon en Inglaterra un claro ambiente de zozobra, y por tal los motines sobrevinieron repetidamente, hasta el extremo de alarmar al gobierno, por lo que suspendió derechos como el "Habeas Corpus" y decretó la pena de muerte contra los que estando en un corrillo no procedieran a la desbandada una vez recibieran orden directa de la policía [...] (1972, p. 20).

\section{Bolívar, el visionario de oportunidades}


Mientras que la situación económica y política interna de Inglaterra se veía comprometida, allende el Atlántico el escenario no se presentaba mejor.

En 1818 el comandante general de las tropas rebeldes, el general Simón Bolívar, había sido derrotado estruendosamente -otra vez- por las fuerzas realistas en Ocumare, comandadas por el general Pablo $\mathrm{Morillo}^{3}$, tal derrota hizo reflexionar en Bolívar y le tornó a una reestructuración de su estrategia militar; consiente de que sus soldados, hombres generalmente de extracción campesina con poca o nula experiencia militar, no eran competencia para los duros y disciplinados regimientos realistas, se hacía necesario un cambio de estrategia que pudiera poner a nivel las cohortes criollas, pero un intenso programa de disciplina y entrenamiento de la tropa requeriría años, tiempo con el que los rebeldes no contaban.

Aparte de las falencias en la instrucción, otro problema que aquejaba con irritante insistencia a las filas de la revolución era la imposibilidad de mantener la recluta a un nivel óptimo, este contratiempo también agobiaba al mando contrario, tanto que "con frecuencia sucedían numerosas deserciones y cambios de soldados del ejército patriota al realista y viceversa" (Ocampo López, 1981, t. 2, p. 119); y es que en una guerra tan confusa amplios sectores poblacionales preferían mantenerse al margen, al no haber una vigorosa acción de adoctrinamiento fundamental en una 'guerra popular'- la única forma de completar la levée era a través de la simple coacción; con lo que a tropa recién levada, reclutada por la fuerza, le era necesario destinarle tropa para cuidarla. Francisco de Paula Santander, uno de los encargados de la logística en el ejército rebelde lo testimoniaba así: He dado orden al capitán Vegal para que entregue a usted toda la recluta que haya hecho esta gente, es necesario tenerla arrestada y no hacerla salir para ejercicio sino a mañana, medio día y tarde, pues de otro modo no se consigue ni un recluta $[\ldots]$ (p. 310).

Y completaba: Toda la recluta que tenga usted existente en ese cantón la conducirá usted bien escoltada y asegurada a entregarla a disposición del comandante Arredondo en Pore (p. 312).

El rosarino se veía desbordado por la enormidad de la deserción: No respondo de deserción alguna, [...] va usted a recibir diariamente partes de deserciones y sólo ofrezco ser el último que se ausente de esta ciudad, luego que todos los soldados se hayan fugado [...] (p. 43).

Con una tropa en absoluta ignorancia de por qué iban a combatir y sin concedérsele estipendios, la defección sólo era una consecuencia lógica:

\footnotetext{
${ }^{3}$ Llama la atención que en una sociedad tan estrictamente jerarquizada como era la España de la época una figura como Pablo Morillo se haya encumbrado de tal manera y haya alcanzado tanta notoriedad, Morillo sería a lo que en el ejército norteamericano de la actualidad se le llama un Mustang, popular raza de equinos de Estados Unidos, y se refiere a aquellos soldados que remontan la oficialidad provenientes directamente de la soldadesca.
} 
Señor general. Ya por parte del capitán Lamprea, ha sabido usted que la noche del 28 se han desertado con armas y municiones 26 soldados de la primera compañía del 5 batallón. La noche del 29 se desertó otro soldado de la 4 y es muy regular que en las siguientes continúen las deserciones. No debe atribuir usted a otra causa semejantes excesos, sino a la falta de dinero y la de víveres [...] en semejante situación no es extraño que un hombre sin principios como es el soldado, abandone el servicio para ir a buscar el sustento a otra parte. Usted sabe que en ninguna parte del mundo hay tropas de línea sin prest y ración (Montaña, 1989, p. 16).

Es en este momento en que la situación en Inglaterra se agrava, y el Libertador, sumando dos más dos, ve la oportunidad de reforzar su maltrecha fuerza e introducir en sus tercios la tan necesaria táctica profesional europea, amén de aumentar sus menguados contingentes; para combatir a los soldados que habían desafiado con valentía a las fuerzas del pequeño general se hacía pues necesario oponer a otros que lo habían hecho con igual éxito ante las fuerzas galas.

Si bien hay voces que aseguran que la idea de involucrar soldados ingleses en la lucha contra España provino de oficiales extranjeros ya presentes en el Estado Mayor de Bolívar, estas sólo tienen como fuente en la cual apoyarse la misma aseveración de los extranjeros en sus memorias; de estas últimas es el oficial de artillería francés Ducoudray Holstein el que se autoproclama como gestor de la idea:

[...] Poco tiempo después de nuestra llegada a Carúpano, un día vi que Bolívar estaba solo y de buen humor. Tras hablar de algunos temas sin importancia, le hablé de un plan que yo tenía para formar una legión extranjera. La organización de esa legión debía adaptarse al tipo de guerra que estábamos haciendo, a la naturaleza geográfica y a los recursos que podíamos sacar de ella le dije francamente que esto que llamábamos nuestro ejército no era otra cosa que una masa de hombres mal vestidos, mal instruidos, y que además no cobraban ningún sueldo (1831, p. 326).

Varias de las investigaciones referentes al tema toman como válido tal testimonio, pero al no haber un contraste entre fuentes nos inclinamos a adjudicar la paternidad de la idea a Bolívar"; éste, aun antes de iniciarse el experimento

\footnotetext{
${ }^{1}$ A propósito de este personaje y de su participación en el Estado Mayor de la tropas republicanas Perú de Lacroix hace una referencia: "Bolívar tiene una pésima opinión de Ducoudray, al serle preguntado por la actuación de este como su edecán, Bolívar afirmó que este nunca lo había sido, ni había merecido su confianza. "Ducoudray Holstein me conoció en Cartagena en el año de 1815 y después de la evacuación se me presentó de nuevo en Los Cayos, cuando estaba yo preparando mi primera expedición para la isla de Margarita. Lo admití, porque entonces todos los que se presentaban para ayudarme eran bienvenidos; lo puse en el Estado Mayor, pero nunca tuve confianza en él para nombrarlo mi edecán; por el contrario, tenía una idea bien poco favorable de su persona y de sus servicios, pues me lo figuraba como una especie de caballero de industria, que vino a engañarme con falsos despachos, pues me habían asegurado algunos que los que presentaba no eran suyos". De Lacroix, Luis Perú. (1999). Diario de Bucaramanga. Bogotá: Fundación para la investigación y la cultura. p. 75. Más adelante Ducoudray se verá envuelto en un confuso incidente que versaba sobre el encumbramiento de Brión a la comandancia general, ver: Lecuna, Vicente. (1950). Crónica
} 
expedicionario, había buscado el concurso diplomático de la Albión, no hay que olvidar que estuvo en Londres en misión diplomática y que repetidamente buscó el apoyo tanto militar como político de Inglaterra, "sólo Gran Bretaña dueña de los mares puede protegernos contra la fuerza unida de la reacción europea" (Lecuna, 1950, p. 89), escribiría más adelante; para ello invistió a Luis López Méndez, vestigio en Inglaterra de la misión venezolana de 1810, a que ganara para la causa rebelde a aquellos soldados en el paro; para ello le confirió un poder amplio y generoso:

[...] En consecuencia nombramos y constituimos a los expresados señores Luis López Méndez y Andrés Bello por ausencia o muerte del primero, agentes y comisionados especiales de la República de Venezuela en la ciudad de Londres, autorizándolos para que con arreglo a las instrucciones que les cometemos puedan otorgar jurídicamente todo genero de escrituras y obligaciones a nombre de la República del modo y con las condiciones que le parezcan [...] (ADYC, 1819 . 1824, f.n).

Inmediatamente López se puso en contacto con los periódicos más influyentes y de tendencia whig, más propicios a la causa rebelde.

Michael Rafter, biógrafo de Gregor MacGregor, uno de los más quijotescos expedicionarios reproduce el esquema de la prensa de la época para llamar a posibles candidatos:

Soldados efectivos cesantes y jóvenes de espíritu harían bien en dirigir su atención a las ventajas no comunes que son ofrecidas ahora para entrar al servicio de la Nueva Granada, las cuales son infinitamente superiores a cualquier otra, ya que después de cinco años, poseerán provisiones suficientes para ellos y su familia para siempre (Rafter, 1820, p. 140).

El Correo del Orinoco, el periódico de los rebeldes, reproduce un artículo del Times de Londres informando sobre los militares que embarcaban hacia América, en éste se comenta la gran profusión de embarcados hacia América y se infiere que el entusiasmo es generalizado:

[...] La gran cantidad de buques, hombres y armas que en los tres últimos meses han dejado nuestras costas para el teatro de guerra en la América del Sur parece tener una influencia preponderante sobre la disposición especulativa y aventurera de nuestro país. Buques de gran porte bien tripulados y bien armados continúan en dar la vela unos tras de otros no sólo del Río Támesis, sino también de varias otras partes del Reino Unido [...] (1819).

De entre los periódicos de la época que publicaban anuncios descollaba el Carrick Morning Post, que tan tarde como 1820, cuando ya Bolívar había instruido en

razonada de las guerras de Bolívar. (3 tomos). New York: The Colonial Press Inc. t. I, p. 123, y Lecuna, V. (Comp) (1929). Cartas del Libertador. (8 Vols). Caracas: Litografía y Tipografía del Comercio. p. 280. 
múltiples comunicaciones a López sobre suspender el envío de soldados ingleses seguía éste diario publicando llamamientos:

[...] Se concederán los incentivos más favorecedores a aquellos hombres jóvenes, de buen carácter, a los que se considere calificados para servir en la Legión Irlandesa del general Devereux, y que estén próximos a zarpar directamente hacia los cuarteles del jefe supremo, solamente se deben presentar hombres efectivos y llenos de vida; se dará preferencia a soldados bien disciplinados, que tengan sus altas en regla, para quienes ésta será una excelente oportunidad de mejorar su fortuna y hacerse a generosas comisiones por el resto de su vida [...]

El anuncio de la propuesta de López llenó de agitación a la city, todo Londres se sintió atraído por la aventura que significaba el embarcar hacia América:

[...] Fue tal el entusiasmo despertado que aquellas propuestas se conocieron rápidamente entre las clases sociales y se comentaron en todos los lugares públicos con singular simpatía. Llegaron hasta el punto de hacer de todo ello una fantasía, como imaginar un existente "dorado," las minas de Potosí y en general, que el porvenir sería próximo y poderoso [...] (Echeverri, 1972, p. 14).

La situación rayaba en la irrealidad, los londinenses empezaron a imaginar todo tipo de aventuras y a fantasear con los supuestos tesoros de la América:

[...] Era tal el juego de la imaginación entre los posibles combatientes que deseaban viajar a América, que en sus mentes bullían cosas mitológicas, como la adquisición de grandes palacios, pedrerías de incalculable valor, vellocinos de oro, alimentos que alargaban la vida y productos panaceos para evitar las enfermedades y alejar los malos espíritus; en fin, nunca pensaron en las penalidades, en lo que un trópico inhóspito les podía ofrecer en conjunto con la sinfonía de las plagas y las miasmas deletéreos [...] (Cuervo, 1938, p. 348).

\section{El Reclutamiento}

A la hora de reclutar posibles soldados no se ahorraban promesas, se aseguraba que la guerra ya estaba prácticamente ganada y que nada más llegar serían otorgadas tierras, en fin que la lucha en América sería una parada militar (p. 348). Las condiciones de contrato se hicieron rápidamente conocidas:

Desde el día en que inscribieran sus nombres recibirían cuatro peniques adicionales por cada chelín más que en el ejército británico; un pasaje hasta los cuarteles, y 60 dólares al llegar; 1 libra de carne de res o de cerdo, 1 libra de pan, 1 1/2 patatas, 1 porción de whisky por día; avena y mantequilla, etc., durante la travesía. Igualmente recibirían una participación proporcional de las tierras, capturas y premios en dinero; 200 acres de tierra, más 80 dólares para comprar implementos de agricultura. La garantía plena de no ser 


\section{trasladados a otros cuerpos sin su connivencia y amplio apoyo a todos aquellos que recibiesen heridas en servicio*.}

Dispensa plena y permiso para vender la tierra, con un pasaje gratis de regreso, de ser necesario, después de cinco años de servicio. Un cabo recibiría 25 acres, un sargento 300, un mayor 350, y así proporcionalmente. Todo cabo bien recomendado sería ascendido a sargento y todo sargento a mayor, y así sucesivamente, además tendrían una enorme posibilidad de ascenso de acuerdo con la conducta "gallarda y digna de un soldado" (Hasbrouck, 1928, p. 47).

Antes de seguir adentrándonos en la temática de los legionarios sería conveniente aclarar que aquellos que embarcaron hacia Sudamérica lo harán bajo la figura del mercenario, un mercenario es definido como alguien que sirve en un ejército por dinero; esta significación se presta a ambigüedades ya que siendo así se englobaría también a todos los que pertenezcan a una fuerza armada nacional. Al respecto se refiere el profesor Alberto Flórez Malagón:

Tradicionalmente, los mercenarios han sido definidos como "extranjeros" contratados para tomar parte directa en conflictos armados. Su principal motivación es la ganancia monetaria, más que la lealtad a un estado-nación, o a su proyecto. Así, los mercenarios aparecen sobre todo en conflictos para estatales, aunque este no es su único campo de acción [...] los grupos mercenarios no se imponen a sí mismos sino que son buscados, encontrados y contratados como una manera de conducir operaciones militares, tanto externa como internamente, como cualquier fuerza militar regular (Flórez, 2000, p. 90).

Más adelante ésta vaguedad en la contratación será causal de discordia ya que el alto mando patriota esperaba que los que se habían embarcado por dinero, lucharan por amor a la causa, a la que probablemente adherían pero su principal interés era la soldada, misma que en todo caso pocas veces recibieron.

Cuando López proclamó que una naciente República requería de cuantos quisieran ayudarle en su lucha contra España no sólo los soldados en el paro respondieron al llamamiento, y al tiempo que los simples milites también acudieron "contratistas militares" ofreciendo sus servicios a López Méndez, simultáneamente a estos los comerciantes londinenses sacaban su ganancia. En una empresa ya bien cargada de tintes mercantilistas los negociantes locales de la city incoaron, aun más si cabe, el enardecimiento de la masa por la proyectada expedición, con el extenso material remanente de las guerras napoleónicas, los mercantes de Londres se beneficiaron enormemente de los enlistados en una inesperada oportunidad de deshacerse de los ingentes excedentes de la guerra que su desmedida ambición les había llevado a adquirir:

[...] exhibiendo en sus vidrieras una gran variedad de uniformes, a cual más ostentoso que el otro. Se exhibían en las vitrinas de los almacenes y con ello se impresionaba al público de donde salían los candidatos para nuevos enganches. Las sillas y aperos de la caballería ofrecidos superaban en lujo a

\footnotetext{
* El subrayado es del autor.
} 
los de los Corassers Franceses o a los Húsares Ingleses, ni hablar de los sombreros que profusamente enjaezados más parecían pertenecer a un ejército de opereta o a un cuerpo de Bersaglieris (Cuervo, 1938, p. 352).

Los ingleses se esforzaban por ataviar a sus tropas con la mayor galanura posible; para la época era práctica corriente el dotar a los regimientos de vistosos y extravagantemente coloridos uniformes; por ejemplo, el del cuerpo de Artillería del coronel Gilmore era igual al del Royal Artillery; el coronel Hippisley adoptó para sus Húsares, un bello uniforme verde oscuro con cuello escarlata para la chaqueta, mangas y solapas con alamares dorados, así como los puños, un elegante nudo austriaco en el brazo, y pantalón verde oscuro con franja dorada, cíngulo carmesí y botas Wellington (p. 349), el del coronel Wilson para sus Húsares constaba de chaqueta escarlata con franjas azul claro y cordones dorados, pantalones escarlata con franjas doradas, para los días de parada, y para el servicio ordinario, uniforme de paño azul, con franjas de oro. Buscando un efecto sicológico se lindaba con el ridículo. Gerhard Masur, uno de los incontables biógrafos de Bolívar anota que: "Se encargaron equipos de gala y de campaña, más adecuados para la guardia de Buckingham Palace que para mercenarios en las selvas del Orinoco" (Masur, 1999, p. 264).

El asunto de los uniformes muestra hasta donde llegaba la ignorancia de los organizadores de los cuerpos en cuanto al destino que les esperaba, aparte que se evidencia la desidia de los enviados americanos frente a los expedicionarios; lo que no deja de plantear la cuestión de si la organización de la expedición fue llevada a cabo con profesionalismo por parte de los representantes americanos, ya que si bien los ingleses no conocían América, perfectamente habrían podido tener la asesoría de los enviados criollos.

Estos uniformes eran inútiles en un teatro de guerra como lo era el trópico; al cabo de un año se habían convertido en jirones y sólo fueron útiles -para los que aún los conservaban, ya que no era raro que los legionarios tuvieran que venderlos para poder comer- en el ascenso a Pisba, e incluso hay los que llegaron a Bogotá en la virtual desnudez.

Como Luis López era el representante de una nación en la cual muy pocos creían y como su crédito en los círculos financieros de la city estaba cada día más en entredicho, la participación de terceros era de inevitable obligatoriedad.

La mayoría, por no decir que la totalidad, de las transacciones que López llevaba a cabo, -adquirir todo lo concerniente a un ejército que va a entrar en campaña- las hacía abonando pagarés, pagarés que vencían en pocos meses, al no poder cumplir López con los compromisos varias veces cambió su casa de Grafton Street por la cárcel:

No existió, en lo que a esa primera expedición se refiere un control de los gastos por parte de López o de sus tenientes. El costo promedio de un equipo completo para un oficial era de 40 libras, siendo que el precio estándar era de la mitad, de la misma manera eran elevados los otros utensilios necesarios 
como sables, lanzas, piedras de chispa, pólvora, plomo, etc., etc. [...] Naturalmente el vendedor aumentaba el precio del artículo en relación con el riesgo que corría al abrirle crédito a un gobierno no bien cimentado, y estipulaba altísimos intereses sobre el capital, que no representaba el valor de los artículos suministrados (p. 350).

Sobre el asunto de los contratistas militares cabe mencionar a Gregor MacGregor, John Devereux, quién ya había estado en América; y el coronel James English. Pero aparte de estos tres también estuvieron otros de los que podríamos nombrar al coronel Hippisley, el coronel Campbell, el coronel Wilson, el coronel Skeene, el coronel Elsom, el coronel Uslar y muchos otros coroneles ya que López "tenía una fábrica de coroneles en producción continua" (p. 348).

Poco a poco se iban consolidando las tropas inglesas, se organizaron los cuerpos llamados Húsares Rojos, Lanceros Venezolanos, Regimientos de Rifles, Húsares Venezolanos así como los cuerpos de artillería y un proyectado cuerpo de oficiales que comandaría un batallón de rifles constituido por tropa nativa; en teoría esta primera expedición estaría al mando de Gustavus Hippisley, primus inter pares, ya que fue él el primero en llegar a un acuerdo sobre levar tropa con el representante de Bolívar; y si bien entre los enlistados existían oficiales más antiguos y de mayor rango, era Hippisley el jefe nominal, ya que en lo que a las expediciones de ingleses a América se refiere, lo que contaba a la hora de estipular la jerarquía militar no era el tiempo de servicio prestado otrora en el British Army, sino el tiempo servido a la República y a Méndez.

Sobre el asunto de la antigüedad anota Hasbrouck: Among the other colonel's, however, jealousy was rife, and the question of seniority tended to embitter their relations toward one another (Hasbrouck, 1928, p. 51).

\section{Consecuencias diplomáticas}

Como la ciudad de Londres se vio agitada por la planeada expedición y como ésta se hacía a plena luz del día, las autoridades españolas tuvieron conocimiento de ella con celeridad; era natural ya que aparte de que todo mundo hablaba de ella, los anuncios que conminaban a los reclutas aparecían con regularidad en los periódicos; además la casa del plenipotenciario español, el duque de San Carlos, daba al Támesis y es muy probable que desde su ventana presenciase la partida de los barcos que conducían a los expedicionarios; así al menos lo deja colegir en su comunicación a Lord Castlereagh, ministro de exteriores de Inglaterra, Hasbrouck acota al respecto:

On October 12th, 1817 he (el embajador español) wrote a confidential letter to Lord Castlereagh, the foreign secretary, protesting against the embarkation from British ports of officers and marines destined to South America, and requesting that the prince regent suspend temporarily permission to export arms and munitions to the west indies, and that prohibit officers on half pay from making long voyages; he declared "it seems that all the population is engaged in this occupation of sending one or another expedition to aid the 
insurgents. The "Two Friends" has been followed by the "Gladwin" and the "Morgan Rattler", and today they prepare the "Prince" and the "Amelia Wilson", and other vessels to convoy at least four cadies of officers and non commissioned officers and complete equipments for regiments of hussars and lancers, and even for three brigades of artillery. In fact we can say that all ships which sail for St. Thomas, Santo Domingo and other points in the West Indies, with cargoes of arms and ammunition, have on board half pay officers in charge of the succours for the insurgents (p. $55-56$ ).

En la misma comunicación, el duque se queja del escandaloso parcialismo de los periódicos, en especial del Times "que abiertamente hace propaganda a la causa insurgente y publica avisos llamando a antiguos soldados a enlistarse".

En un principio la actitud del gobierno británico para con los expedicionarios era de disimulada aquiescencia. Con una economía en franca recesión e ingentes cantidades de licenciados desocupados en las calles de los principales centros urbanos, cualquier alivio que ayudase a sobrenadar el desastre era bien recibido; los comerciantes estaban saliendo de las enormes existencias que habían acumulado durante la guerra, los licenciados estaban encontrando una forma de ganarse la vida, y sobre todo, los astilleros y dueños de barcos estaban beneficiándose con el pasaje de aquellos que querían ser parte de la aventura. Este último gremio fue el que más se afectó ${ }^{2}$ cuando las reiterados reproches de las autoridades españolas en Londres obligaron al gobierno a tomar cartas en el asunto; todos se estaban beneficiando, pero una reclamación de ese tipo, al alto nivel de embajadores, no se podía pasar por alto, más cuando en el papel España todavía era un aliado y un fuerte bastión conservador de los intereses de las monarquías en Europa.

Una demostración de fuerza por parte del stablishment inglés se hacía necesaria, y es por ello que el 17 de noviembre de 1817, el príncipe regente, emitirá una proclama que prohibirá a los súbditos británicos tomar parte en la lucha entre España y sus dominios de ultramar (Webster, 1925, p. 243), del mismo modo el ministerio de guerra dispuso que antes de pagar a los half pay oficcers -miembros del ejército a un nivel de semi retiro- estos declararan no estar al servicio de un gobierno extranjero (Cuervo, 1938, p. 355), edictos que no molestaron en lo más mínimo el embarque de los mercenarios, ya que el gobierno inglés tenía problemas internos más apremiantes. Pero para 1819 ante el alistamiento en España de la expedición de Cádiz, el parlamento, acuciado por el gabinete emitió una mucho más agresiva y radical medida: la Foreign Enlistment Bill, que prohibía de manera taxativa y sin cortapisas, so pena de graves sanciones económicas y penales a los que la infringieran, el reclutamiento de ingleses para luchar en América. Esta volte à face de los ingleses es sencilla de explicar. Albión decidió cuidarse las espaldas y ofrecer a Fernando todas las ventajas posibles para el triunfo de éste, así podía recuperar la credibilidad que había perdido con la alianza y lavarse las manos ante un eventual éxito de los españoles; y si la expedición de

\footnotetext{
${ }^{2}$ A tanto llegó su reclamo ante lo que consideraban una directa lesión a sus intereses que elevaron una protesta formal por las medidas anti expedicionarias.
} 
Cádiz no prosperaba el camino para el reconocimiento diplomático y la ampliación exponencial del prometedor mercado latinoamericano estaba expedito; mirase por donde se le mirase, Albión saldría ganando.

\section{Viajando hacia América}

Incluso antes de embarcar los problemas de logística patentizaron la desorganización y la pobre planificación de la empresa, de los seis barcos presupuestados para partir, el Emerald y el Prince tuvieron que permanecer en puerto mientras se recolectaba el resto de las provisiones, el médico de la expedición -un redomado charlatán- recolectó dinero entre la tripulación para comprar medicamentos especiales, volando con 15 libras y cuanto pudo arrastrar (Restrepo, 1969, p. 608). Peor sino tuvo el Indian, naufragó y se llevó con él a todo el Húsares Venezolano (Cuervo, 1938, p. 359). Cuando por fin partían hacia América, -destino mismo que era utópico ya que ni López ni los expedicionarios tenían idea de a donde llegarían- las desgracias lejos de terminar se multiplicaban; cuando en Madeira los hombres de Hippisley desembarcaron para recabar provisiones su desordenado comportamiento negó el derecho de tocar tierra a los que le siguieron (p. 359); el alcohol, la indisciplina y los absurdamente reiterados duelos entre los embarcados fueron la constante, Hippisley, como jefe nominal de la expedición trató de atajar la anarquía reinante pero como ninguno de los coroneles se sentían sus subordinados, el desorden prosiguió hasta que los capitanes de los barcos impusieron el orden, pretextando que las continuas reyertas entorpecían el manejo de los barcos (p. 359).

Cuando arribaron a las Antillas lo que sobrevivía de marcialidad en los hombres se diluyó; en las islas no había quien les diera razón de a donde dirigirse o a quien presentarse (p. 359). Al respecto de la llegada de los legionarios de Hippisley, Robert Harvey, autor de Los Libertadores, una voluminosa obra sobre los protagonistas de la epopeya americana se pronuncia:

Cuando los barcos llegaron a las Indias occidentales -Haití, Trinidad y Granada-, los legionarios fueron recibidos con indiferencia o abierta hostilidad. Les dijeron que Venezuela era una jungla indomable de crueldad, osos salvajes, indios desnudos y enfermedad. El Libertador, un loco sádico. En las islas, la deserción acabó con muchas unidades y cantidad de reclutas murieron de viruela, fiebre amarilla, tifus, malaria y disentería. En Haití, las brigadas de fusileros y artilleros se desintegraron por completo (2002, p. 173).

El gobernador de Granada les autorizó a romper los compromisos y eso marcó la pauta para el caos (Cuervo, 1938, p. 360). Antes de enfrentarse con el enemigo la primera cohorte de refuerzos extranjeros había desaparecido. Esto se mostraría profético.

Algunos decidieron enfilar hacia las posesiones inglesas en el Caribe y probar suerte allí, otros como el navío, Britannia fijaron rumbo a Puerto Príncipe para vender su carga y recuperar lo recuperable. Los artilleros se disolvieron, el coronel 
Gilmore, su jefe, decidió que poca utilidad tenían los artilleros sin cañones; y los barcos tampoco se salvaron de la subasta, sus capitanes preferían venderlos a los corsarios patriotas que seguir arriesgándolos, caso del Emerald que fue vendido a Brión en Santa Lucia.

Sobre esta primera $-y$ modélica- expedición hace la final acotación Cuervo Márquez:

Todos los regimientos y escuadrones sufrieron tantas perdidas por las enfermedades y las deserciones, que de 500 oficiales y tropa llegados a la isla de San Bartolomé en el Britannia, Dowson, Prince, Emerald, solamente 150 siguieron para Angostura donde estaba el Cuartel General del Libertador ( $p$. 360).

Esta tropa restante, los flamantes húsares ingleses, fue conducida por los coroneles Hippisley y Wilson y al mando de ellos llegaron al Orinoco. Posteriormente aquellos que no habían querido desembarcar y se habían encaminado a las Antillas se reengancharon de nuevo, engrosando las filas de los patriotas; estas islas fueron el primer filtro -muchos más les esperarían- por el que pasaron los mercenarios, las enfermedades cobraron su cuota y con sus organismos debilitados por la larga y penosa travesía, aquellos no pudieron oponer resistencia.

\section{El encuentro con la revolución}

Cuando al fin se unían a la tropa rebelde, y cuando creían que sus padecimientos finalmente tocarían a su fin estos no hacían más que empezar. Se desembarcaba con la prefabricada idea de que en América abundaban las oportunidades de enriquecerse y de medrar al amparo de la revolución o con su simple procedencia europea. Las esperanzas de comodidad o de mínimo bienestar se desvanecían al ver el Cuartel General del Jefe Supremo, allí los llaneros -que constituían la masa de soldadesca rebelde- vivían en las más básicas condiciones, manteniéndose en sus más ancestrales costumbres, como un soldado cronista de la época lo describe:

Allí se vivía la vida primitiva y guerrera de campaña en el Llano; carne salada o tasajo, plátano, yuca, a veces arroz o casabe ${ }^{6}$, panela, café, cuando podían tener esas delicadezas. Se dormía a la sombra de un árbol o a plein air en los raros momentos de reposo (p. 361).

Y sobre el llanero se manifestaba en los siguientes términos:

El soldado soportaba la lluvia o el sol ardiente con el mismo estoicismo, y ninguna penalidad lo hacía vacilar en la lucha emprendida. Atravesaba a nado los ríos caudalosos, donde abundaba el caimán, el pez eléctrico o el pequeño Caribe, más peligroso, porque en nubes se precipita sobre cualquier herida

\footnotetext{
${ }^{6}$ El tasajo es carne en tiras, salada y secada al sol. El casabe es una preparación que se hace con la yuca.
} 
que mane sangre, y en pocos minutos reduce la bestia o el hombre a los pocos huesos. La mitad de la vida la pasaba a caballo, y era la lanza, que manejaba con una destreza aterradora, su arma de combate. El llanero patriota fue de una fidelidad irreductible: lo mismo en la victoria que en la derrota, seguía a su jefe y no vacilaba en sacrificarse por él, fuera en la desgracia o en la prosperidad (p. 361).

Pasaba el tiempo y a los soldados no les llegaba la paga lo que los iba tornando nerviosos; Hippisley, un bon vivant se amargaba por esta circunstancia y reflexionaba sobre el alto tratamiento postal que se le daba, a lo que él decía: "A todos esos homenajes epistolares hubiera preferido que se me pagaran uno dólares de más, para haberme procurado de algunas comodidades indispensables, unas pocas botellas de vino, un buen pato, un pavo, jamón, huevos, todo lo que hace falta en una mesa" (Reyes, 2004, p. 164). Más adelante diría: "Nada se conseguía, excepto carne dañada; pero ni pan, ni harina, ni legumbres, ni arroz, sal o pimienta, ni azúcar, velos o sopas, y ni siquiera licores. ¿Pero era que no existían esos artículos y otros? Claro que sí, aunque a precios inmensos" (p. 180) ${ }^{7}$. No obstante mostraba algo de humanidad y consideración por sus compañeros, "peor era la situación de mis compañeros subalternos, a los que se les demoraba o negaba el pago de su salario o parte de él, que esperaban desde su llegada a Angostura" (p. 160).

Otra de las situaciones que chocaban con las altas pretensiones del británico era el alojamiento; es la tradición que la oficialidad y la tropa regular se alojen de manera separada; pero cuando una pequeña tropa que este comandaba regresó a Angostura desde San Fernando la falta de alojamiento obligó a romper con la tradición, ya que "No se trataba de una vivienda individual; oficiales y suboficiales, junto con sus esposas fuimos hacinados en un solo cuarto, grande es verdad, pero común para todos [...] El cuarto adyacente lo ocupaban siete oficiales recién llegados de Inglaterra. El segundo ayudante general se me acercó para decirme que inmediatamente conseguiría una orden, de modo que yo pudiera mudarme con algunos de mis oficiales a una cámara especial" (p. 179).

Siempre era difícil el que los oficiales encontrasen un alojamiento acorde a su rango; si contaban con suerte algún lugareño de origen o con simpatías hacia Inglaterra los invitaba a ser sus huéspedes; de lo contrario quedaba lo usual, dormir en hamaca o en chinchorro, y no pocas veces a plein $a i r^{8}$.

Las quejas del coronel no cesaban y mientras tanto las estrecheces de los soldados proseguían:

\footnotetext{
${ }^{7}$ El ejército patriota compuesto en su gran mayoría por llaneros se habituaba con facilidad a la dieta, siempre habían hecho de la carne su principal alimento y el que de repente este se convirtiera en el único no les causaba gran disgusto; la razón de tan monótona dieta era que los campos en su mayoría se encontraban incultos, la anárquica situación del país impedía el normal desarrollo de las actividades agrícolas, además de la disponibilidad de brazos, resultante de todo esto que lo único disponible eran las cabezas de ganado que prácticamente se habían convertido en silvestres.

${ }^{8}$ Para oficiales acostumbrados a un excelente trato en las campañas europeas, aquello era inadmisible.
} 
Los oficiales empezaron a vender sus vestidos; la comida era tan mala que todos la consideraban insuficiente hasta para sobrevivir e incluso el ron que necesitábamos para beber el agua malsana del Orinoco se nos escatimaba ( $p$. 166).

Incluso la llegada de la paga no garantizaba el que esta tuviese alguna utilidad:

[...] Pay was often in arrears, and even when it was distribuited at the rate of half a month's pay per month, it come in the form of money made locally out of some base metal washed with silver wich the tradesmen refused to receive, except at a large discount [...] (Hasbrouck, 1928, p. 86).

La inacción era la nota predominante en las autoridades criollas, cualquier reclamación era escuchada con oídos sordos y el evadir responsabilidades la regla:

Aquí nadie hace nada, cualquiera que sea la importancia de los asuntos a tratar, el mismo día que se introduzca la solicitud [...] La palabra "mañana" es de uso permanente, y tan continuamente se emplea en la conversación, que uno al oírla no sabe si reír de ellos o indignarse (Fortique, 1972, p. 33).

Por esos días el gobernador Mariano Montilla ordenó a los británicos comparecer a un desfile de adhesión a la causa; craso error porqué los que menos estaban contentos con ella eran los ingleses, sufrimiento tras sufrimiento y decepción tras decepción habían causado en ellos un hondo rechazo a la causa, al fin y al cabo eran mercenarios y si bien puede que hubiesen albergado algún afecto por la revolución su objetivo fundamental era el salarium y si hasta este se les negaba el único camino que les quedaba era esa ancestral tradición soldadesca llamada motín:

Después de que los oficiales prestaron juramento, les tocó el turno a los suboficiales y, entonces todos aquellos pertenecientes a los húsares rojos se negaron a prestar el juramento, a menos que recibieran siquiera parte de los 80 dólares que a cada uno le había prometido López Méndez en Londres (Reyes, 2004, p. 166).

Montilla no sabía que hacer, acuarteló a las tropas y emplazó cañones frente a los barracones de los ingleses, les confiscó los sables y les prohibió uso de uniforme; la situación era potencialmente explosiva, pero los oficiales superiores salvaron la situación compartiendo su menguado prest con los soldados y todo se solucionó con muchos ¡Viva la República! y ¡Vivan los Patriotas! (p. 167)

\section{No tengo nada que otorgarle pero le compro el sombrero}

Un episodio que por lo pintoresco merece la pena transcribirse ocurrió cuando Hippisley se entrevista con el jefe, lo que marcará la despedida del inglés de las fuerzas patriotas ya que en ésta ante las "minuciosas y detalladas cuentas" del inglés, Bolívar reacciona con desdén -comportamiento previsible en una persona 
tan poco cuidadosa con el dinero- y reclama; $1^{\circ}$ que las cuentas no llevasen la firma de López y $2^{\circ}$ la extrañeza del jefe ante el hecho de que tales desembolsos no los hubiese hecho el mismo López, Hippisley le contestó, por medio del interprete, -el coronel Rooke- "que en verdad no tengo la firma de Méndez en estas cuentas, pues tanto él como yo las consideramos innecesarias" y en cuanto a lo segundo el británico replicó "que el señor Méndez no hubiera podido obtener en Inglaterra crédito de bancos o de comerciantes, ni siquiera por 10 libras esterlinas" (p. 181).

Para ese momento la situación de la tropa había pasado de crítica a desesperada y los soldados ingleses estaban al borde de la inanición, los oficiales ingleses que llegaban, rápidamente informados de lo que sucedía solicitaban su pasaporte para retornar lo más pronto posible; viendo esto Bolívar pensó en dispersar a los legionarios, Hippisley agrega:

[...] Me vi obligado a divulgar entre todo el regimiento, el remate de mis vestidos, mis sabanas, mis armas, mis monturas, etcétera, con el fin de conseguir fondos para tener, por lo menos, medicinas y medios para comprar un pasaje hacia alguna de las Indias Occidentales. Logré vender la mayor parte de mis cosas y regalé otra porción a los oficiales amigos (p. 181).

Hippisley era un incordio y sus repetitivos requerimientos condimentados con dosis de posible coacción del gobierno inglés hicieron que Bolívar desesperara y respondiera: "Si los actos del gobierno de Venezuela no cuentan en Inglaterra, otro tanto pasa con los del gobierno británico en Venezuela" (Masur, 1999, p. 266).

La paciencia de Bolívar se agotó, lo que le llevó a responderle al inglés que:

El gobierno de Venezuela jamás ha engañado a nadie; pero si ha sabido castigar la insolencia de aquellos que lo ofenden.

Tiene Vd. razón en esperar que yo no haré nada para llevarlo a Vd. a la desesperación; si $\mathrm{Vd}$. se desespera será por otras causas que yo ignoro, o tal vez no.

No negaré la justicia que $\mathrm{Vd}$. merece, porque tengo suficiente dignidad para reconocerla; pero no a causa de sus ridículas amenazas, que desprecio.

Se le concede licencia y pasaporte para que se retire del ejército, siempre que haga dimisión de su empleo y renuncie a las estipulaciones del contrato (Reyes, 2004, p. 158).

La conversación sólo estuvo sazonada por la oferta de Bolívar de comprar el sombrero del inglés, que usó obstinadamente durante varios días.

Al llegar a Londres, Hippisley demandó a López Méndez por incumplimiento de contrato y escribe el libro " $A$ narrative of the expedition to the rivers Orinoco and Apure, in South America; joined to the patriotic forces in Venezuela and Caracas, by Gustavus Hippisley, late colonel of the first Venezuelan hussars in the service of the republic and colonel commandant of the British Brigade in South America". 
Más adelante su hijo, Gustavus Butler Hippisley se alineará con su padre, y harán de lanzar invectivas a Bolívar una tradición familiar.

\section{El incidente Wilson}

Pero hubo peores situaciones que la de Hippisley; Henry Wilson, uno de los miembros de la Legión Albión provocó a Páez para que destronara del mando supremo a Bolívar, Daniel Florencio O'Leary que estaba presente recogió en sus memorias el acontecimiento:

Al día siguiente de que el general Bolívar se embarcara rumbo a Angostura, Páez pasó revista a sus tropas. Vestía una casaca verde mal cortada, con cuello y puños rojos, abrochada con pequeños botones amarillos; pantalones vaqueros blancos, calcetines de algodón del mismo color y zapatos con espuelas de plata. En la cabeza llevaba un sombrero español de tres picos, con encaje plateado. El caballo parecía bueno y estaba engualdrapado con muchos adornos de plata.

Pocos días después comió con el coronel Wilson, bajo una gran sombra frente a la casa del coronel. Wilson lo aduló de la manera más empalagosa. Al general no pareció disgustarle más bien lo aceptó como el sincero elogio que de verdad merecía. Esa tarde se acordó que Wilson y los oficiales de Apure le proclamarían como capitán general del ejército. Se señaló un día a principios de la semana siguiente para celebrar la ceremonia. Convocaron a varios de los jefes de Apure que estaban a mano y ellos llevaron a todos los llaneros que pudieron conseguir.

Era sin duda un grupo pintoresco. Siete u ocho mil hombres a caballo, todos mal vestidos, algunos casi desnudos, formados de cualquier manera sin ningún orden, en una planicie al este de la ciudad. Nuestros batallones formaban a la derecha en honor, supongo, a nuestros espléndidos uniformes. Cuando la farsa estaba a punto de comenzar se presentó Páez acompañado por treinta o cuarenta oficiales y ayudantes de campo. El general fue saludado con vítores entusiastas y, tan pronto como cesaron, se leyó el acta que lo nombraba capitán general. A continuación hubo otra salva de vítores y se dio la orden de que los jinetes más expertos hicieran una demostración. Terminada la ceremonia en el campo, los jefes se reunieron para firmar el acta. Así comenzó nuestra carrera en favor de la independencia sudamericana!

Como es natural, Páez estaba encantado con sus nuevos auxiliares ${ }^{9}$. Sin embargo apenas acabado el día, alguien le susurró al oído que se estaba equivocando. Por consideración se decidió mandar el acta al cuartel general y requerir el permiso de Bolívar para aprobar el nuevo grado. Mientras tanto, Wilson hizo prometedoras ofertas. Llegaría un cuerpo de varios miles de ingleses. Wilson obtuvo permiso para viajar a Angostura, con la recomendación de que el general Bolívar atendiera sus propuestas.

\footnotetext{
${ }^{9}$ Páez siempre ejerció una fuerte atracción en los legionarios ingleses que le conocían; Hippisley relata que cuando le conoció echaba espuma por la boca y acababa de matar a 40 españoles. Como las tropas dispersas que iban llegando a Angostura eran remitidas a San Fernando donde estaba destinado Páez este formó una guardia de honor con ellos y de ellos aprendió el uso del tenedor y unas cuantas palabras en inglés.
} 
Salió de Achaguas pero, al llegar a la capital, los castillos en el aire se vinieron abajo. Wilson fue arrestado y remitido al fuerte de Guayana la Vieja, hasta que apareció una nave que zarpaba rumbo a Europa. Lo embarcaron y lo destituyeron del servicio. Paez recibió una reprimenda y ahí acabó el asunto (O'Leary, 1952, pp. 489 - 490).

Pero el asunto no se quedó allí; cuando Wilson llegó a Londres se dedicó a practicar el deporte favorito de los legionarios veteranos: acusar a López de estafa, López contrarrestó los ataques divulgando por la prensa anuncios en donde decía que los soldados que habían ido a América lo habían hecho por propia voluntad y que el no podía responder por aquellos que se habían embarcado con contratistas; así mismo acusó a Wilson de estar en inteligencia con el embajador español para sembrar la discordia y la intriga entre los jefes rebeldes, sobre lo cual alegaba poseer pruebas (Cuervo, 1938, p. 367).

Lo que llama la atención de todo el suceso ciertamente no es la perfidia del inglés -los británicos tienen cierta predisposición natural a ella- sino la blandura de Bolívar para con Páez comparado a otros que cometieron faltas más leves y que si bien fueron acusados de intentar usurpar las funciones de Bolívar, nunca lo hicieron de la manera frontal que lo hizo Páez; Richard Vawell, oficial inglés al que ya hemos aludido confirma la debilidad de la posición militar de Bolívar frente Páez y la autoridad de este sobre la tropa. Cedeño, uno de los jefes de los llanos, por esos días se había tornado muy impopular entre la tropa y al llegar al cuartel fue vilipendiado por los llaneros:

Estábase a punto incluso de maltratarle, cuando sus guardias de corps, noticiosos de lo que ocurría, llegaron inmediatamente de su campamento, establecido en las cercanías, y entrando al galope en la población, entablaron una escaramuza en las calles con los que habían insultado a su jefe. El tumulto se hizo tan serio, que Bolívar se encerró en sus cuarteles.

Sin embargo, Páez, que sabía hacerse temer y respetar por los soldados, se lanzó en medio de los más furiosos, y tomando de la mano a Cedeño, que estaba pálido y tembloroso, le sustrajo con unas cuantas palabras solamente a la amenazadora multitud que le rodeaba. Arrestó en seguida a los oficiales más culpables de los dos bandos, quienes obedecieron sin murmurar. Entre los arrestados figuraban dos coroneles del mismo Paez, por los que sentía particular afecto: el uno era Arizmendi, hombre apuesto e inteligente, y el otro Castro, quien, años después, fue nombrado por Bolívar gobernador de la provincia de Cauca.

Una vez dadas estas severas órdenes, Páez hizo embarcar a Cedeño en una lancha cañonera y le aconsejó que se retirase a San Fernando. Este incidente, que pudiera haber acarreado las más enojosas consecuencias, fue así prontamente sofocado por la conducta decidida de Páez, que había adquirido sobre sus tropas un ascendiente irresistible

Durante esta tumultuosa escena, Bolívar estuvo encerrado en su casa con sus ayudantes de campo y sus secretarios, y por la noche embarcó en una chalupa y marchó a Angostura.

Súpusose entonces que no juzgó prudente permanecer sin guardias de campo o sin tropas con las que pudiera contar entre los Llaneros, que eran 
exclusivamente afectos a sus jefes, tales como Rangel, Carbajal, Juan Gómez y Páez (p. 40 - 41).

Expediciones e Itinerarios (1817-1819).

Expedición encabezada por

coronel Hippisley

coronel English

coronel Elsom

Número de soldados

general D'Evereux

720

1200

general MacGregor

572

coronel Meceroni

1729

Varios

600

Gran Total:

300

387

5508

\section{Conclusiones}

Después de Hippisley vendrán varias expediciones más, en la intención de llegar a engrosar las filas rebeldes y abrazar la causa republicana, pero los dolores de cabeza que causaron y su constante indisciplina hicieron que el jefe desistiera finalmente de la idea.

Expediciones como la del "gallardo" coronel English que impidió, con su negativa a suministrar artilleros, un movimiento táctico que buscaba caer por la espalda a los realistas y que obligó a Urdaneta a pronunciarse en los siguientes términos:

[...] No es posible abrir la campaña sobre un territorio enemigo con un cuerpo de tropas que se cree autorizado para denegarse al Servicio que se le señala, sino la acomoda, ni mucho menos, si los Gefes de este Cuerpo miran como una desmembración de él qualquiera partida que se destine a qualquiera servicio o comisión [...] La iniciativa de la insubordinación de la Legión Británica en la falta momentánea del pan en un solo día en Pampatar, y la venida de dichos Gefes al Norte aquel mismo día dejando al pueblo entregado al Saqueo como se hizo en Porlamar, hizo variar el plan de operaciones prevenido por el Gobierno [...] Aquella iniciativa de insubordinación corroborada con la inadmisión tumultuaria del comandante general de Caballería; la representación hecha por algunos oficiales superiores reclamando el ascenso sobre el que todos han recibido al embarcarse para Venezuela, y la conducta poco regular de las tropas en qualquier momento en que se halla retardado alguno de los artículos de subsistencia (que nunca han sido más de una falta momentánea) y últimamente la negativa de los artilleros han puesto al Gefe de la Expedición en estado de dudas qué partido podría sacar la República de un cuerpo de tropas que reclama las menores faltas en su subsistencia, que resiste cumplir qualquier orden que no le acomode, que se juzga auxiliar sin serlo, que se cree desmembrado al separarse qualquiera partida a qualquier servicio [...] (Historical Archive Ireland, 1819). 
La de Devereux y su Legión Irlandesa que, presa de la más vergonzosa indisciplina, tomó a saco Riohacha, ciudad que los recibió como salvadores y que tuvo que aliarse con la derrotada guarnición realista para desalojar a sus "liberadores" y de la cual Bolívar dijo:

[...] Nada de lo que V[ste]d dice de la Legión irlandesa lo he extrañado: todo lo temía de esos verdugos, que sí no les pagan no matan que son como aquellas cortesanas que no se rinden sino después del cohecho. Así he visto con placer la separación de esos viles mercenarios y, por el contrario, vería con horror que deshonrasen aun éstas filas después de los exesos cometidos en Río Hacha [...]" (Montilla, 1982, pp. 226 - 227).

O la de MacGregor, aquel escocés al que las autoridades criollas, hartas de sus excesos se referían así:

Me intereso vivamente para que se le conceda su licencia a Gregor. Este farol - Quixote o que se yo que diablos me tiene harto. Este hombre no puede servirnos, por lo menos en la Nueva Granada sino para ponernos en 10 mil comprometimientos (Cacua Prada, 1983, p. 80).

Después ocuparía Riohacha y se haría llamar Inca de la Nueva Granada, posteriormente fundaría una monarquía -la de Poyais- en la Florida ${ }^{10}$.

El clima y la exótica fauna diezmaban con rapidez a los expedicionarios, exhaustos por la travesía, sus débiles organismos no podían resistir tanto la hostilidad del trópico como la monótona dieta:

Después de mi regreso a los cuarteles del general English desde el norte, pasé frente a varias carpas convertidas en hospitales, aunque en la situación de miseria más grave, donde carecían de todo. Los desafortunados pacientes estaban tendidos sin cobijas sobre el frío suelo, sin nada para cubrirse, la mayoría de ellos volviéndose locos; varios estaban tendidos ya muertos o moribundos, bajo los espinosos perales o bajo cualquier otra cosa donde pudieran protegerse de los abrasadores rayos del sol (Fortique, 1972, p. 37).

Aparte estaba la misma guerra; para aquellos que habían combatido en las guerras napoleónicas era imposible conciliar el nivel de barbarie y sadismo al que había llegado la guerra:

La exterminación parece ser el primordial objetivo de cada bando con relación al oponente y los informes restos humanos, visibles en todas partes, prueban el éxito con que ellos han alcanzado su objetivo. Atravesando la llanura, galopando por la maleza escalando la montaña, la vista se detiene

\footnotetext{
${ }^{10}$ Para un acercamiento más profundo ver: Browm, M. (2005). "Inca, Sailor, Soldier, King: Gregor MacGregor and the early nineteenth century Caribbean". En Bulletin of Latin American Research, Vol. 24, No 1. p. 4-71. Para una mirada a la juventud de Gregor MacGregor, se puede ver "Autobiographical Segment", John MacGregor Papers, National Archives of Scotland, GD 50/112, GD 50/ 184/104, f. 2. Adjunto se encuentra esbozado el siguiente capítulo que hablaría de su paso por el ejército británico, pero su deceso le impidió escribirlo. Aparte del material que está en Escocia también hay documentos conservados en el Archivo General de la Nación, Venezuela, Caracas, Ilustres Próceres, Vol. 49, f.. 2-80.
} 
continuamente ante el espectáculo de pila sobre pila de huesos humanos de ambos sexos y de todas las edades (p. 37).

De los usos criollos en la guerra el que más deploraban los legionarios era la decapitación:

Este es un procedimiento en el cual muchos suramericanos son expertos. El prisionero está de pie, aunque en ciertas ocasiones le permiten arrodillarse; en seguida viene un individuo con una espada, probablemente con un cigarro en la boca, y le asesta una tajada certera en la nuca que siempre mata, y con frecuencia separa enteramente la cabeza del cuerpo (p. 93).

Pero entonces teniendo en cuenta estos tropiezos hay que preguntarse si el experimento expedicionario fue exitoso o de lo contrario en que radicó su fracaso.

Ciñéndonos a lo estrictamente militar hay que concluir que la experiencia no cumplió con las expectativas que generó; el problema era que la táctica de guerra europea era casi imposible de introducir en los tercios criollos. Los tácticos ingleses no pudieron insertar en los ejércitos republicanos las formas militares de vanguardia. El problema era tanto de impedimenta como de hombres, la situación de la tropa rebelde siempre fue precaria, constantemente escaseaba la pólvora, pocas veces había rancho y virtualmente nunca prest, de hecho los modos estándar de combate occidentales no penetraran en nuestro país sino hasta el siglo XX, cuando en 1907 se constituya la primera academia militar, gracias a la ayuda del ejército chileno. Sólo a partir de este momento es que se evidencia un ejército coherente, profesionalizado e institucionalizado, casi 100 años después de su mítico nacimiento.

Que la organización militar sólo haya encontrado un norte recién en el siglo XX, patentiza la reacción que la clase militar demostraba frente a una estructuración exportada directamente de Europa.

La idiosincrasia del soldado y del oficial rebelde durante la guerra revolucionaria, impidió la compenetración de formas de conducir los combates a la manera europea, de conceptos más avanzados.

Estos -los criollos- preferían mantener el statu quo militar del momento: grados militares autoproclamados, ascensos y distinciones no siempre influidos por la valentía 0 el profesionalismo y la ausencia absoluta de una clase militar enteramente formada para y en el arte de la guerra.

Al ser fallidos los intentos de instituir academias militares, la clase militar no tuvo la influencia de las escuelas militares, que ante todo inculcan en el futuro oficial el spirit de corps y la instrucción necesaria para llevar a cabo una guerra regular.

Además, dichas instituciones instruyen a sus miembros a abstenerse del ejercicio político; los soldados, según este planteamiento, pelean las guerras, más no las declaran; éste sería el trabajo de los políticos y si bien éstos pueden y deben tener 
injerencia en los asuntos militares, -"la guerra es un asunto muy serio para dejárselo a los militares" dicen que dijo Clemenceau- lo contrario no puede suceder y el ejército debe ser esencialmente apolítico.

La ausencia de academias militares organizadas e institucionalizadas podría ser una de las razones de los traumáticos acontecimientos decimonónicos así como del nefasto caudillismo.

De otra parte el haber abandonado la táctica criolla -disparo a lo parto, emboscadas, celadas, lanzas, machete y malicia- habría significado el final de los esfuerzos militares criollos. Si bien los tercios rebeldes habían sido varias veces vapuleados por los realistas, esto ocurría cuando los criollos resolvían entrar a combatir a la europea. La línea que hasta el momento se seguía -la táctica de guerrilla- era la más indicada y al final fue la que decidió la suerte de la guerra.

Por otro lado los soldados de Morillo, que habían diezmado a las fuerzas galas con tácticas guerrilleras, renunciaron a una estrategia probadamente exitosa y eficaz a favor de los modos tradicionales europeos, con lo que la iniciativa le fue devuelta a los criollos; si bien es cierto que los soldados que a América llegaron no eran los "bandidos de Andalucía", era Morillo, el comandante general, uno de los jefes guerrilleros más reputados de la reacción anti francesa.

En cuanto al arte militar, éste indica que una fuerza de combate tiene que estar acorde con el terreno sobre el cual dicha fuerza va a utilizarse ${ }^{11}$ los Llanos y en general todo el terreno donde desplegarán su accionar las fuerzas rebeldes era ideal para practicar la táctica militar desarrollada por los patriotas; de hecho era más fácil, -como en efecto ocurrió- que los militares europeos se adecuaran a hacer la guerra criolla. Es teniendo en cuenta lo anterior que salta a la luz la verdadera utilidad de los legionarios, la de vindicar con su presencia la legitimidad de la revolución.

Al involucrar a soldados ingleses Bolívar -astutamente- estaba descubriendo a la opinión pública internacional, sobre todo a la europea y particularmente a la inglesa, que una guerra en toda regla estaba ocurriendo allende los mares. Una guerra entre países, en las que uno de los contendientes estaba tan legitimado que súbditos de monarquías europeas corrían con presteza a prestar su socorro, tan convencidos estaban de la causa a la que se estaban uniendo, causa que, en todo caso, iba en contra de la política internacional oficial que sus países de origen sostenían hacia el exterior. Con ello se estaban ganando adeptos, simpatías que siempre despierta en la gente de la humanidad una lucha con visos de parecerse a la de David contra Goliat.

\footnotetext{
${ }^{11}$ Aserto verificable en experiencias de la actualidad en donde se utilizan ejércitos desarrollados para otros contextos, en teatros de guerra totalmente contrarios, caso de la invasión a Irak por parte de los E.E.U.U., o nuestro propio conflicto.
} 
Aparte de todo, los países de la Europa postnapoleónica estaban prestando un creciente interés hacia la dirección que la opinión pública doméstica tomaba, especialmente Inglaterra, que veía que su asombroso proceso de industrialización y desarrollo había creado una nueva clase social, clase que podía ser el vehículo perfecto en donde incubase el proceso de descontento o de revolución.

Y que dicho sea de paso, los ingleses al insertarse en los tercios criollos estaban desechando, casi como de un plumazo, las tesis de Madrid que argüían que el conflicto en las colonias "era un simple malentendido entre sus posesiones de ultramar y la metrópoli" y que estaba dirigida "por elementos descontentos y muy alejados del sentir popular que guardaba fidelidad al soberano".

Así lo refrenda Masur:

[...] Frente a la reducida cantidad de tropas repartida por el continente para luchar por la libertad de América, los números también representaban un papel importante. Los cuatro mil europeos que habían venido a luchar contra Bolívar resultaron un elemento vital en el crisol del futuro americano. Bolívar lo sabía perfectamente. En cierta ocasión expreso que el verdadero libertador de Sudamérica no era él, sino López Méndez, que era quien había enviado a la Legión Británica ${ }^{12}$. Otro tanto cabe decir de la importancia inmediata de esta legión en el cuadro militar. Para Bolívar tenía un significado más intrínseco. En un momento dado, cuando nadie podía pensar aún en el reconocimiento internacional de los Estados libres de Sudamérica, la participación de los voluntarios europeos dio a esos Estados un sentido histórico. El prestigio que la Legión Británica aportó al mundo de Bolívar fue semejante al aportado por Lafayette al mundo de Washington (1999, p. 268).

Tampoco es que su aporte militar haya sido nulo, fuerzas combativas como los batallones rifles compuestos por tropa criolla y cuadros extranjeros lo refrendan, así mismo la visión de foráneos sobre la revolución ha ayudado a generaciones de historiadores a escribir la historia de la guerra de independencia sudamericana, y esta visión así muchos la descalifiquen y desdeñen como equívoca es de por sí valiosa por provenir de individuos no nacidos en América.

El siglo XIX fue un siglo que le perteneció a Inglaterra, ningún acontecimiento de esa época le pasará por alto, y el que milites británicos hayan estado insertos en la guerra de independencia contra España, pondrá de manifiesto la importancia que estos territorios tenían como futuros mercados, así como el ominoso hecho de que Inglaterra les acompañaría desde el mismo momento de su creación, sólo para ser relevada por EEUU. Sobra decir que este acompañamiento estaba mediado por el interés y fue negativo en su mayoría.

\section{Fuentes documentales}

\footnotetext{
${ }^{12}$ Masur equivoca el concepto cuando cree que Bolívar alude al papel de Méndez en la legión; la frase de Bolívar, tan reproducida en los libros de historia, iba direccionada a hacer hincapié en el esfuerzo de López en la consecución de armas, dinero, pertrechos y demás, no en hombres.
} 
Archivo Diplomático y Consular del Ministerio de Relaciones Exteriores de Colombia, (ADYC). Fondo Legaciones en Europa. Bogotá.

Carrick Morning Post. (1820). Irlanda

Correo del Orinoco. Bogotá: Archivo General de la Nación.

English Papers. Historical Archive of Ireland. Recuperado el 19 de enero de 2008 de http://www.nationalarchives.ie/index.html

Holstein, D. (1831). Histoire de Bolívar par le général Ducoudray Holstein; continuée jusqu'a sa mort, (2 vol) París : Alphonse Levasseur, Libraire, Au Palais Royal.

Diarios de Campaña, Libros de Ordenes y Reglamentos Militares, 1818 - 1835. (1988). Bogotá: Biblioteca de la Presidencia de la República.

Rafter, M. (1820), Memoirs of Gregor MacGregor, comprising a sketch of the revolution in New Granada and Venezuela, with biographical notices of generals Miranda, Bolivar, Morillo and Horé, and a narrative of the expeditions to Amelia island, Portobello, and Rio de la Plata, interspersed with revolutionary anecdotes. London: J.J. Stockdale.

\section{Bibliografía}

Atehortúa Cruz, A. L. (2004). "Las fuerzas armadas en Colombia". En Análisis Político, № 51. Bogotá: IEPRI, Universidad Nacional de Colombia.

Barriga Del Diestro, F. (1998). Finanzas de nuestra primera independencia. Bogotá: Editorial Guadalupe.

Cacua Prada, A. (1983). Custodio García Rovira, El estudiante mártir. Bogotá: Plaza y Janes.

Cuervo Márquez, L. (1938). Independencia de las colonias hispanoamericanas, Participación de la Gran Bretaña y de los EEUU, Legión Británica. 2 tomos. Bogotá: Editorial Selecta, Bogotá.

De Lacroix, L. P. (1999). Diario de Bucaramanga. Bogotá: Fundación para la investigación y la cultura.

Echeverri M., A. Sangre irlandesa en Antioquía, Biografía del Dr. Hugo Blair Brown, miembro de la legión británica y médico coronel de los ejércitos patriotas. Medellín: Academia antioqueña de historia, Medellín. 
(1982). General de división Mariano Montilla, homenaje en el Bicentenario de su nacimiento, 1782 - 1982. 2 vols. Caracas: Ediciones de la Presidencia de la República.

Flórez Malagón, A. G. (2000, septiembre). "Las fuerzas mercenarias en las luchas de independencia del siglo XIX". En Memoria y Sociedad, Vol. 4, (№ 8). Bogotá: Pontificia Universidad Javeriana, Bogotá.

Fortique, J. R. y Roberton, J. (1972). Cirujano del Ejército de Bolívar. Maracaibo: Editorial Puente.

Harvey, R. (2002). Los Libertadores, La lucha por la independencia de América Latina 1810 - 1830. Barcelona: R.B.A. Libros S.A.

Hasbrouck, A. (1928) Foreign Legionaries in the liberation of Spanish South America. New York: Columbia University Press.

Lecuna, V. (Comp) (1929). Cartas del Libertador, 8 Vols. Caracas: Litografía y Tipografía del Comercio.

Lecuna, V. (1950). Crónica razonada de las guerras de Bolívar, 3 tomos. New York: The Colonial Press Inc.

Masur, G. (1999). Simón Bolívar. Bogotá: Fundación para la investigación y la cultura FICA.

Montaña, A. (Comp) (1989). Santander y los ejércitos patriotas 1811-1819. Bogotá: Biblioteca de la Presidencia de la República, Bogotá, 1989.

Montgomery, B. L. (1968). La Historia de la Guerra. Madrid: Editorial Aguilar.

Ocampo López, J. (1981). "El proceso militar y político de la Independencia". En Jaramillo Uribe, J. (Eds). Manual de Historia de Colombia (3 tomos). Bogotá: Colcultura.

Ocampo López, J. (1994a). Historia básica de Colombia. Bogotá: Plaza y Janes Editores.

Pardo Rueda, R. (2004). La guerra en la historia. Bogotá: Ediciones B de Colombia.

Restrepo, J. M. (1969). Historia de la revolución de la República de Colombia. (4 vols). Medellín: Editorial Bedout.

Reyes Duarte, H. (2004). Las bestias negras del Libertador. Bogotá: Editorial Temis. 
Webster, C. K., (1925). The foreign policy of Castlereagh, 1815 - 1822, Britain and European alliance. London: $\mathrm{G}$ Bell and sons.

Fecha de recepción: 15 de abril de 2009

Fecha de aprobación: 21 de septiembre de 2009 